\title{
Management of Central Precocious Puberty in Children with Hypothalamic Hamartoma
}

\author{
Junghwan Suh (D), Youngha Choi, Jun Suk Oh, Kyungchul Song (D, Han Saem Choi, Ahreum Kwon, \\ Hyun Wook Chae $(D)$ and Ho-Seong Kim *(D)
}

Citation: Suh, J.; Choi, Y.; Oh, J.S.; Song, K.; Choi, H.S.; Kwon, A.; Chae, H.W.; Kim, H.-S. Management of Central Precocious Puberty in Children with Hypothalamic Hamartoma. Children 2021, 8, 711. https://doi.org/10.3390/ children 8080711

Academic Editor: Marco Carotenuto

Received: 24 June 2021

Accepted: 17 August 2021

Published: 18 August 2021

Publisher's Note: MDPI stays neutral with regard to jurisdictional claims in published maps and institutional affiliations.

Copyright: (c) 2021 by the authors. Licensee MDPI, Basel, Switzerland. This article is an open access article distributed under the terms and conditions of the Creative Commons Attribution (CC BY) license (https:// creativecommons.org/licenses/by/ $4.0 /)$.
Department of Pediatrics, Severance Children's Hospital, Endocrine Research Institute, Yonsei University College of Medicine, Seoul 03722, Korea; suh30507@yuhs.ac (J.S.); younghachoi1986@gmail.com (Y.C.); joojang87@naver.com (J.S.O.); endosong@yuhs.ac (K.S.); hansaem6890@yuhs.ac (H.S.C.); armea@yuhs.ac (A.K.); hopechae@yuhs.ac (H.W.C.)

* Correspondence: kimho@yuhs.ac; Tel.: +82-2-2228-2069

\begin{abstract}
Hypothalamic hamartoma $(\mathrm{HH})$ is a rare, congenital, and benign lesion of the tuber cinereum, typically presenting with central precocious puberty (CPP), gelastic seizure, and developmental delay. This study aimed to investigate CPP in HH patients and compare clinical features between before and after gonadotropin-releasing hormone $(\mathrm{GnRH})$ agonist treatment. A total of $30 \mathrm{HH}$ patients under 18 years of age who visited Severance Children's Hospital between January 2005 and May 2020 were retrospectively reviewed. Fourteen patients were male (46.7\%) and sixteen (53.3\%) were female, with a mean age at diagnosis was4.2 \pm 2.9 years. During follow-up, 24 patients $(80.0 \%)$ were diagnosed with CPP, 15 patients (50.0\%) had gelastic seizure, and 13 patients (43.3\%) had developmental delay. The gelastic seizure was significantly associated with sessile type $\mathrm{HH}$ rather than pedunculated type $\mathrm{HH}(85.7 \%$ vs. $18.8 \%, p=0.001)$. After GnRH agonist treatment, discrepancies between bone age and chronological age decreased ( $3.3 \pm 1.3$ years to $2.0 \pm 1.7$ years, $p=0.002)$. Additionally, height standard deviation score for bone age was increased, and predicted adult height increased significantly in females, while males showed an increasing trend. Clinical symptoms of $\mathrm{HH}$ were closely associated with the location of $\mathrm{HH}$, and $\mathrm{GnRH}$ agonist treatment was safe and effective in the management of CPP caused by $\mathrm{HH}$.
\end{abstract}

Keywords: hypothalamic hamartoma; central precocious puberty; gelastic seizure

\section{Introduction}

Hypothalamic hamartoma $(\mathrm{HH})$ is a rare, congenital, and benign lesion of the tuber cinereum. It is mainly composed of normal brain tissue, such as neurons, glial cells, and fiber bundles [1]. The prevalence of $\mathrm{HH}$ varies between 1 in every 50,000 and 1 in every 200,000 persons [2-4]. The majority of $\mathrm{HH}$ is located at the base of the hypothalamus and the floor of the third ventricle [5]. It is usually diagnosed by brain magnetic resonance imaging (MRI) scans and is seen as non-enhancing, isointense, or hyperintense lesions on T2-weighted images [6,7].

$\mathrm{HH}$ is a complex neuroendocrine disease that usually first presents with one of the three following main symptoms; central precocious puberty (CPP), gelastic seizure, or developmental delay [8,9]. HH is one of the most common organic causes of CPP [10]. CPP caused by $\mathrm{HH}$ tends to occur significantly earlier in life than idiopathic CPP [11]. The pathophysiology of hypothalamus-pituitary-gonadal axis activation is not completely understood, but CPP in HH patients is well managed by treatment with a gonadotropinreleasing hormone $(\mathrm{GnRH})$ agonist $[12,13]$. Gelastic seizure, also known as laughing seizure, is a distinct feature of $\mathrm{HH}$ [14]. Other various seizure types including generalized or focal seizures are reported in $\mathrm{HH}$ patients [15]. As antiepileptic drugs are frequently unsuccessful in seizures associated with $\mathrm{HH}$, surgical intervention is often considered in intractable epilepsy $[4,16]$. Additionally, behavioral and cognitive disorders are often 
accompanied in $\mathrm{HH}$ patients with seizure events, resulting in developmental delay and diverse psychological problems $[2,17]$.

Previously published research has reported case studies with $\mathrm{HH}$, but most of these studies focused mainly on seizure control, neuroimaging, and surgical management. Previous studies focusing on $\mathrm{CPP}$ in $\mathrm{HH}$ are sparse, while studies concerning longitudinal follow-up data of CPP patients are especially rare. In this study, clinical characteristics, laboratory results, and image findings of $\mathrm{HH}$ are explored. Further, we investigated $\mathrm{CPP}$ in $\mathrm{HH}$ patients and compared clinical features between before and after GnRH agonist treatment.

\section{Materials and Methods}

\subsection{Patients}

A total of 30 patients under 18 years of age with $\mathrm{HH}$ who visited Severance Children's Hospital between January 2005 and May 2020 were retrospectively reviewed. The diagnosis of $\mathrm{HH}$ was based on MRI scans. This study was approved by the Institutional Review Board of Severance Hospital, Yonsei University College of Medicine in Seoul, Korea (no. 4-2020-0241). The requirement to obtain informed consent was waived.

\subsection{Study Design}

Patient data, including sex, age at symptom onset, age at diagnosis, symptom at first visit, additional symptoms during follow-up, and type of received treatment, were reviewed. Additionally, brain MRI findings such as size and type of $\mathrm{HH}$ were gathered. $\mathrm{CPP}$ was diagnosed when the peak LH level was $5 \geq \mathrm{IU} / \mathrm{L}$ on GnRH stimulation test before 8 years of age in girls and before 9 years of age in boys. In CPP patients, further clinical and biochemical data were collected, including age at diagnosis of CPP, height, weight, body mass index (BMI), serum luteinizing hormone ( $\mathrm{LH})$, follicle-stimulating hormone (FSH), prolactin, estradiol, testosterone, peak LH level on GnRH stimulation test, pubertal development stage, bone age, and duration of GnRH agonist treatment.

Brain MRI scans were acquired using a Philips 3.0T scanner (Philips Achieva 3.0T; Philips Medical Systems, Best, The Netherlands). Type of $\mathrm{HH}$ was determined based on brain location on MRI, and cases were classified into either pedunculated (parahypothalamic) type or sessile (intrahypothalamic) type [6,8,9]. Height standard deviation score (SDS) for chronological age, height SDS for bone age, weight SDS, and BMI SDS were calculated using the growth standard of Korean children and adolescents [18]. Serum LH, FSH, and prolactin levels were measured using sequential 2-step immunoenzymatic assays (Access Reagent Pack, Beckman Coulter Inc., Brea, CA, USA), with an intra-assay coefficient of variation $(\mathrm{CV})$ of $3.5-5.4 \%$, inter-assay $\mathrm{CV}$ of $4.3-6.4 \%$, and a lower limit of detection of $0.2 \mathrm{IU} / \mathrm{L}$ for both gonadotropins. Serum E2 levels were measured using radioimmuno assays (Coat-A-Count Estradiol, Siemens, Erlangen, Germany), and serum testosterone levels were measured by chemiluminescent microparticle immunoassays (Architect i2000 analyzer, Abbott Diagnostics, Chicago, IL, USA). Pubertal development was determined using the Marshall and Tanner staging system [19,20]. Bone age was examined by performing radiography of the left hand and wrist and interpreted using the Greulich and Pyle (GP) method [21]. Predicted male and female adult height were estimated using the Bayley-Pinneau (BP) method [22]. All patients with CPP were treated with GnRH agonist every four weeks, either leuprolide acetate $(3.75 \mathrm{mg})$ or triptorelin acetate $(3.75 \mathrm{mg})$. GnRH agonist treatment was maintained until bone age reached 12 to 12.5 years in girls and 13 years in boys.

\subsection{Statistical Analysis}

Statistical analyses were performed using IBM SPSS ver. 25.0 (IBM Corp., Armonk, NY, USA). Anthropometric data, hormone levels, size of $\mathrm{HH}$, tanner stage, bone age, and predicted adult height are presented as the mean \pm SD. Fisher's exact test was used to analyze the association between clinical symptoms and type of $\mathrm{HH}$, and the paired 
t-test was applied to compare data before $\mathrm{GnRH}$ agonist treatment and after treatment. A $p$-value $<0.05$ was considered statistically significant.

\section{Results}

\subsection{Clinical Characteristics of Patients with $\mathrm{HH}$}

Among the total $30 \mathrm{HH}$ patients, 14 patients were male (46.7\%) and 16 patients were female $(53.3 \%)$. Mean age at onset of first symptom was $2.9 \pm 2.5$ years, and age at diagnosis of $\mathrm{HH}$ was $4.2 \pm 2.9$ years. Twelve patients (40.0\%) came to the hospital presenting precocious puberty as a first symptom, while nine patients $(30.0 \%)$ had a gelastic seizure as the chief complaint for the first visit. Seven patients presented with other types of seizures, such as generalized tonic-clonic seizure $(n=3)$, simple partial seizure $(n=2)$, focal seizure $(n=1)$, and infantile spasm $(n=1)$. During the follow-up, 24 patients $(80.0 \%)$ were diagnosed with CPP, 15 patients (50.0\%) had gelastic seizure, and 13 patients $(43.3 \%)$ had developmental delay. Twelve patients $(40.0 \%)$ had surgical operation, and two patients (6.7\%) underwent gamma-knife surgery. All 24 CPP patients received GnRH agonist treatment. Two patients were diagnosed with growth hormone deficiency by growth hormone stimulation test and received growth hormone treatment (Table 1).

Table 1. Characteristics of patients with hypothalamic hamartoma.

\begin{tabular}{lc}
\hline \multicolumn{1}{c}{ Characteristics } & Value \\
\hline Sex & \\
Male/Female & $14(46.7 \%) / 16(53.3 \%)$ \\
Age at symptom onset (year) & $2.9 \pm 2.5$ \\
Age at diagnosis (year) & $4.2 \pm 2.9$ \\
Symptom at first visit & \\
Precocious puberty & $12(40.0 \%)$ \\
Gelastic seizure & $9(30.0 \%)$ \\
Other seizures & $7(23.3 \%)$ \\
Headache & $1(3.3 \%)$ \\
Developmental delay & $1(3.3 \%)$ \\
Symptoms during follow-up & \\
Precocious puberty & $24(80.0 \%)$ \\
Gelastic seizure & $15(50.0 \%)$ \\
Developmental delay & $13(43.3 \%)$ \\
Treatment & \\
Surgical operation & $12(40.0 \%)$ \\
Gamma-knife surgery & $2(6.7 \%)$ \\
GnRH agonist treatment & $24 / 24(100 \%)$ \\
Growth hormone treatment & $2(6.7 \%)$ \\
Type of hypothalamic hamartoma & \\
Pedunculated/Sessile & $16(53.3 \%) / 14(46.7 \%)$ \\
Size of hypothalamic hamartoma (mm) & $17.8 \pm 9.2$ \\
\hline Data are prosented as mean \pm SD 0 number of
\end{tabular}

Data are presented as mean \pm SD or number of patients (\%).

\subsection{Association between Clinical Manifestations and Type of $\mathrm{HH}$}

Type of $\mathrm{HH}$ was classified into pedunculated type or sessile type according to its location on brain MRI scans. Of the 30 patients, 16 patients (53.3\%) had pedunculatedtype $\mathrm{HH}$ while 14 patients $(46.7 \%$ ) had sessile type. Mean size of $\mathrm{HH}$ was $17.8 \pm 9.2 \mathrm{~mm}$ (Table 1). Association between the type of $\mathrm{HH}$ and the classic triad of symptoms (precocious puberty, gelastic seizure, and developmental delay) is summarized in Table 2. Pedunculated type of $\mathrm{HH}$ had a higher prevalence of precocious puberty than sessile type $(87.5 \% \mathrm{vs}$. $71.4 \%)$, but the difference was not significant $(p=0.378)$. Twelve of fourteen patients $(85.7 \%)$ with sessile type $\mathrm{HH}$ had gelastic seizure, while only three of sixteen $(18.8 \%)$ pedunculated-type patients presented gelastic seizures $(p=0.001)$. Developmental delay 
showed a preponderance of sessile type over pedunculated type, but the difference was not statistically significant $(64.3 \%$ vs. $25.0 \%, p=0.063)$.

Table 2. Association between type of $\mathrm{HH}$ and symptom triad.

\begin{tabular}{lccc}
\hline & Sessile Type & Pedunculated Type & $p$ Value \\
\hline Precocious puberty & $10 / 14(71.4 \%)$ & $14 / 16(87.5 \%)$ & 0.378 \\
Gelastic seizure & $12 / 14(85.7 \%)$ & $3 / 16(18.8 \%)$ & 0.001 \\
Developmental delay & $9 / 14(64.3 \%)$ & $4 / 16(25.0 \%)$ & 0.063 \\
\hline
\end{tabular}

\subsection{Management of Central Precocious Puberty in HH Patients}

Among the $24 \mathrm{CPP}$ patients, 11 patients $(45.8 \%)$ were male, and 13 patients $(54.2 \%)$ were female. Mean age at diagnosis of CPP was $5.7 \pm 3.1$ years. Basal LH level was $2.48 \pm 1.31 \mathrm{IU} / \mathrm{L}$, estradiol was $25.74 \pm 23.00 \mathrm{pg} / \mathrm{mL}$, and testosterone was $227.26 \pm 291.82 \mathrm{ng} / \mathrm{dL}$. LH peak of GnRH stimulation test was $27.92 \pm 18.94 \mathrm{IU} / \mathrm{L}$. Breast tanner stage on diagnosis of CPP was $2.8 \pm 0.6$ and testis size was $12.1 \pm 7.1 \mathrm{cc}$ (Table 3 ).

Table 3. Characteristics of hypothalamic hamartoma patients with central precocious puberty $(n=24)$.

\begin{tabular}{lc}
\hline \multicolumn{1}{c}{ Characteristics } & Value \\
\hline Male/female & $11(45.8 \%) / 13(54.2 \%)$ \\
Age at diagnosis of CPP (year) & $5.7 \pm 3.1$ \\
Basal hormone levels at diagnosis & \\
LH (IU/L) & $2.48 \pm 1.31$ \\
FSH (IU/L) & $4.18 \pm 2.73$ \\
Estradiol $(\mathrm{pg} / \mathrm{mL})(n=13)$ & $25.74 \pm 23.00$ \\
Testosterone $(\mathrm{ng} / \mathrm{dL})(n=11)$ & $227.26 \pm 291.82$ \\
Prolactin $(\mathrm{ng} / \mathrm{mL})$ & $12.95 \pm 7.50$ \\
LH peak of GnRH stimulation test $(\mathrm{IU} / \mathrm{L})$ & $27.92 \pm 18.94$ \\
Breast tanner stage on diagnosis of CPP $(n=13)$ & $2.8 \pm 0.6$ \\
Testis size on diagnosis of CPP $(\mathrm{cc})(n=11)$ & $12.1 \pm 7.1$ \\
Duration of GnRH agonist treatment $($ year $)(n=15)$ & $3.1 \pm 2.2$ \\
\hline
\end{tabular}

$\overline{\mathrm{CPP}}$, central precocious puberty; LH, luteinizing hormone; FSH, follicle-stimulating hormone; $\mathrm{GnRH}$, gonadotropin-releasing hormone. Data are presented as mean $\pm \mathrm{SD}$ or number of patients $(\%)$

Of the 24 CPP patients, 9 patients were referred to other hospitals, and the remaining 15 patients were continuously followed up in our clinic. Patients underwent GnRH agonist treatment for $3.1 \pm 2.2$ years on average (Table 3). Clinical findings of the 15 patients before and after GnRH agonist treatment are presented in Table 4. Height SDS for chronological age decreased after GnRH agonist treatment ( $1.38 \pm 1.76$ to $0.72 \pm 1.38, p=0.010)$, while height SDS for bone age significantly increased $(-2.65 \pm 1.76$ to $-1.43 \pm 1.15, p=0.003)$. Weight SDS and BMI SDS showed no significant change. Bone age was $3.3 \pm 1.3$ years advanced compared to chronological age at diagnosis, which significantly decreased to $2.0 \pm 1.7$ years after GnRH agonist treatment $(p=0.002)$. Predicted adult height significantly increased in females $(149.0 \pm 8.8 \mathrm{~cm}$ to $157.3 \pm 9.7 \mathrm{~cm}, p=0.006)$, while males showed an increasing trend $(171.0 \pm 12.4 \mathrm{~cm}$ to $175.2 \pm 8.3 \mathrm{~cm}, p=0.066)$. 
Table 4. Comparison between before and after GnRH agonist treatment $(n=15)$.

\begin{tabular}{lccc}
\hline & Before GnRH Treatment & After GnRH Treatment & $p$ Value \\
\hline Height $(\mathrm{cm})$ & $123.7 \pm 19.4$ & $141.0 \pm 15.0$ & $<0.001$ \\
Height SDS for chronological age & $1.38 \pm 1.76$ & $0.72 \pm 1.38$ & 0.010 \\
Height SDS for bone age & $-2.65 \pm 1.76$ & $-1.43 \pm 1.15$ & 0.003 \\
Weight (kg) & $30.9 \pm 12.4$ & $44.8 \pm 12.6$ & $<0.001$ \\
Weight SDS & $1.53 \pm 1.17$ & $22.29 \pm 3.37$ & 0.450 \\
BMI & $19.30 \pm 2.88$ & $1.58 \pm 0.94$ & 0.001 \\
BMI SDS & $1.23 \pm 1.26$ & $11.7 \pm 1.9$ & 0.214 \\
Bone age (year) & $9.9 \pm 2.3$ & $9.7 \pm 2.7$ & $<0.001$ \\
Chronological age (year) & $6.6 \pm 3.0$ & $2.0 \pm 1.7$ & $<0.001$ \\
BA-CA (year) & $3.3 \pm 1.3$ & $175.2 \pm 8.3$ & 0.002 \\
Male predicted adult height $(\mathrm{cm})(n=6)$ & $171.0 \pm 12.4$ & $157.3 \pm 9.7$ & 0.066 \\
Female predicted adult height $(\mathrm{cm})(n=7)$ & $149.0 \pm 8.8$ & 0.006 \\
\hline
\end{tabular}

GnRH, gonadotropin-releasing hormone; SDS, standard deviation score; BMI, body mass index; BA, bone age; CA, chronological age. Data are presented as mean $\pm \mathrm{SD}$.

\section{Discussion}

$\mathrm{HH}$ is a rare congenital disease only diagnosed by brain imaging, which makes it difficult to investigate its epidemiology such as prevalence, sex distribution, and clinical features. Some previous studies reported that $\mathrm{HH}$ is slightly more common in males, but the differences were not remarkable. Parvizi et al. reported that 59 of $100(59.0 \%) \mathrm{HH}$ patients were male [15], and Nguyen et al. found that 136 of 256 patients $(53.1 \%)$ were male [4]. However, our study population showed nearly equal distribution among both sexes (14 male patients and 16 female patients). Additionally, $\mathrm{HH}$ is usually confirmed by brain MRI scans during the further evaluation of pubertal development or seizure events, which generally onsets in the early years in life. Corbet Burcher et al. reported that the mean age at symptom onset was 1.5 years based on a systematic review of $264 \mathrm{HH}$ patients, and the mean age at diagnosis of $\mathrm{HH}$ was 2.4 years in their cohort with $46 \mathrm{HH}$ children [17]. Our results showed a mean age of 2.9 years at symptom onset, and age at diagnosis of $\mathrm{HH}$ was 4.2 years, which is slightly older than previous studies $[4,23,24]$.

$\mathrm{HH}$ has often been characterized by its distinct clinical symptoms. The majority of $\mathrm{HH}$ patients first visit hospitals complaining of early pubertal development or seizures. In our study, CPP was the most common first symptom, found in 12 patients, followed by gelastic seizure in 9 patients. However, considering that seven patients experienced other types of seizures at first visit, over half of the patients (16 of 30 patients, $53.3 \%$ ) first presented with seizures. The prevalence of CPP in $\mathrm{HH}$ patients from our study is $80.0 \%$ (24 of 30 patients), which is relatively higher than in previous reports ( 28 of 67 patients, $41.7 \%$ [7], and 46 of 100 patients, $46.0 \%$ [15]). However, some other researches showed a higher prevalence of CPP in HH patients (174 of 277 patients, 62.8\% [4], 115 of 214 patients, $53.7 \%$ [25]). Unlike other previous cross-sectional studies, we continuously followed up $\mathrm{HH}$ patients without $\mathrm{CPP}$ at first visit, and 12 patients had newly developed CPP during the observation. This longitudinal design of this study could have influenced differences in the prevalence of CPP in our $\mathrm{HH}$ patients.

$\mathrm{HH}$ is classified into either pedunculated type or sessile type based on its location in brain MRI scans. The association between the type of $\mathrm{HH}$ and clinical symptoms was investigated in many previous studies, showing a close relationship between pedunculated type $\mathrm{HH}$ and CPP. Further, a high correlation has been reported between the sessile type $\mathrm{HH}$ and gelastic seizure with accompanying developmental delay $[4,8,24-26]$. Our data showed similar results in terms of gelastic seizure, which was highly associated with sessile type $\mathrm{HH}$. Additionally, CPP was more commonly diagnosed in the pedunculated type, but the results were not statistically significant. The developmental delay also showed a tendency toward sessile type $\mathrm{HH}$.

Seizure in $\mathrm{HH}$ patients is often first treated with antiepileptic drugs, but the results are usually unsuccessful $[15,27,28]$. Surgical management is considered in patients with 
medically intractable seizure, which can make epileptic patients seizure-free and improve cognition and behavior problems. Various surgical techniques have been devised, such as microsurgical resection, endoscopic disconnection, stereotactic radiosurgery, radiofrequency ablation, and vagal nerve stimulation [29-31]. In our study, 19 of 30 patients had seizure history, while gelastic seizure was most commonly seen in 15 patients. Among the 19 seizure patients, 12 patients underwent surgical resection, and 2 patients underwent gamma-knife surgery. The mean timing of surgery was 5.7 years after initiation of pharmacological treatment. Among the 14 surgery patients, 8 patients were seizure-free after surgery and 6 patients had improvement of seizure activity. However, we did not observe any changes in seizure patterns in patients with GnRH agonist treatment. None of the $11 \mathrm{HH}$ patients who had no seizure events received surgical intervention.

The mechanism of $\mathrm{HH}$ triggering the onset of puberty is not clearly understood, but there are a few proposed hypotheses. Previous studies suggested that $\mathrm{HH}$ controls GnRH secretion in several ways, such as producing ectopic GnRH within the HH itself or controlling nearby neurons synaptically connected to GnRH neurons [13,31,32]. Research by Chan et al. emphasized that the anatomic features of $\mathrm{HH}$ are more responsible for arousing pubertal development [33]. In any case, whatever the exact mechanism of the onset of puberty in $\mathrm{HH}$ patients may be, CPP caused by $\mathrm{HH}$ is well controlled by $\mathrm{GnRH}$ agonist treatment $[12,23,34,35]$. In our study, 15 CPP patients continuously received GnRH agonist treatment for an average of 3.1 years and had no suspected unexpected serious adverse reactions. All girls had their menarche at a mean duration of 17 months after discontinuation of GnRH agonist treatment. All 15 patients had follow-up brain MRI scans after starting GnRH agonist treatment, and there were no interval changes in $\mathrm{HH}$ size. We used three parameters to evaluate the efficacy of GnRH agonist treatment; the discrepancy between bone age and chronological age, height SDS for bone age, and predicted adult height by the BP method. After GnRH agonist treatment, bone age advancement was ameliorated by 1.3 years, and height SDS for bone age significantly increased. Additionally, predicted adult height by the BP method increased significantly in females, while males showed an increasing, but not statistically significant, trend.

There are some limitations to this study. Among the $24 \mathrm{CPP}$ patients, $9 \mathrm{HH}$ patients with CPP were referred to other hospitals, and the remaining 15 patients received $\mathrm{GnRH}$ agonist treatment continuously in our outpatient clinic. As GnRH agonist treatment is mainly based on monthly injection, patients prefer getting injections at hospitals near their residential area, resulting in a high proportion of follow-up loss. Additionally, we used the $\mathrm{BP}$ method to predict final adult height in $\mathrm{HH}$ patients with CPP. While the BP method is one of the most long-standing and widely used methods to predict adult height, it has some limitations. The BP method was established in the 1950s based on American children, which might be inadequate to apply directly to Korean children in the 21st century. Further, predicted adult height calculation by the BP method is not available in children with skeletal age (bone age) younger than six, and it is impossible to predict adult height in children of extremely high stature by the BP method. Lastly, 4 of 15 CPP patients are still under treatment of GnRH agonist, and 6 patients had surgical operation or gamma-knife surgery, which could have influenced our analysis. Further studies with a larger sample size and a longer follow-up period are required to elucidate more detailed results.

\section{Conclusions}

In summary, we investigated clinical characteristics, laboratory results, and brain MRI findings in $30 \mathrm{HH}$ patients. Gelastic seizure was closely associated with sessile type $\mathrm{HH}$, while CPP showed a tendency toward pedunculated type $\mathrm{HH}$. In addition, based on $15 \mathrm{HH}$ patients with CPP, we can reconfirm the safety and efficacy of GnRH agonist treatment in $\mathrm{HH}$ patients with CPP. 
Author Contributions: Conceptualization, methodology, J.S. and H.-S.K.; formal analysis, investigation, resources, data curation, Y.C., J.S.O., K.S. and H.S.C.; writing-original draft preparation, J.S. and H.-S.K.; writing-review and editing, supervision, A.K., H.W.C. and H.-S.K. All authors have read and agreed to the published version of the manuscript.

Funding: This research received no external funding.

Institutional Review Board Statement: This study was approved by the Institutional Review Board of Severance Hospital, Yonsei University College of Medicine in Seoul, Korea (no. 4-2020-0241). The approval date is 24 April 2020.

Informed Consent Statement: The requirement to obtain informed consent was waived.

Data Availability Statement: The data presented in this study are available on request from the corresponding author.

Conflicts of Interest: The authors declare no conflict of interest.

\section{References}

1. Coons, S.W.; Rekate, H.L.; Prenger, E.C.; Wang, N.; Drees, C.; Ng, Y.T.; Chung, S.S.; Kerrigan, J.F. The histopathology of hypothalamic hamartomas: Study of 57 cases. J. Neuropathol. Exp. Neurol. 2007, 66, 131-141. [CrossRef]

2. Weissenberger, A.A.; Dell, M.L.; Liow, K.; Theodore, W.; Frattali, C.M.; Hernandez, D.; Zametkin, A.J. Aggression and psychiatric comorbidity in children with hypothalamic hamartomas and their unaffected siblings. J. Am. Acad. Child Adolesc. Psychiatry 2001, 40, 696-703. [CrossRef]

3. Brandberg, G.; Raininko, R.; Eeg-Olofsson, O. Hypothalamic hamartoma with gelastic seizures in swedish children and adolescents. Eur. J. Paediatr. Neurol. 2004, 8, 35-44. [CrossRef]

4. Nguyen, D.; Singh, S.; Zaatreh, M.; Novotny, E.; Levy, S.; Testa, F.; Spencer, S.S. Hypothalamic hamartomas: Seven cases and review of the literature. Epilepsy Behav. 2003, 4, 246-258. [CrossRef]

5. Barral, V.; Brunelle, F.; Brauner, R.; Rappaport, R.; Lallemand, D. Mri of hypothalamic hamartomas in children. Pediatr. Radiol. 1988, 18, 449-452. [CrossRef]

6. Boyko, O.B.; Curnes, J.T.; Oakes, W.J.; Burger, P.C. Hamartomas of the tuber cinereum: Ct, mr, and pathologic findings. Am. J. Neuroradiol. 1991, 12, 309-314.

7. Freeman, J.L.; Coleman, L.T.; Wellard, R.M.; Kean, M.J.; Rosenfeld, J.V.; Jackson, G.D.; Berkovic, S.F.; Harvey, A.S. Mr imaging and spectroscopic study of epileptogenic hypothalamic hamartomas: Analysis of 72 cases. Am. J. Neuroradiol. 2004, 25, 450-462.

8. Arita, K.; Ikawa, F.; Kurisu, K.; Sumida, M.; Harada, K.; Uozumi, T.; Monden, S.; Yoshida, J.; Nishi, Y. The relationship between magnetic resonance imaging findings and clinical manifestations of hypothalamic hamartoma. J. Neurosurg. 1999, 91, 212-220. [CrossRef]

9. Mittal, S.; Mittal, M.; Montes, J.L.; Farmer, J.P.; Andermann, F. Hypothalamic hamartomas. Part 1. Clinical, neuroimaging, and neurophysiological characteristics. Neurosurg. Focus 2013, 34, E6. [CrossRef]

10. Partsch, C.J.; Heger, S.; Sippell, W.G. Management and outcome of central precocious puberty. Clin. Endocrinol. 2002, 56, 129-148. [CrossRef]

11. Cassio, A.; Cacciari, E.; Zucchini, S.; Balsamo, A.; Diegoli, M.; Orsini, F. Central precocious puberty: Clinical and imaging aspects. J. Pediatr. Endocrinol. Metab. 2000, 13 (Suppl. 1), 703-708. [CrossRef]

12. De Brito, V.N.; Latronico, A.C.; Arnhold, I.J.; Lo, L.S.; Domenice, S.; Albano, M.C.; Fragoso, M.C.; Mendonca, B.B. Treatment of gonadotropin dependent precocious puberty due to hypothalamic hamartoma with gonadotropin releasing hormone agonist depot. Arch. Dis. Child 1999, 80, 231-234. [CrossRef]

13. Harrison, V.S.; Oatman, O.; Kerrigan, J.F. Hypothalamic hamartoma with epilepsy: Review of endocrine comorbidity. Epilepsia 2017, 58 (Suppl. 2), 50-59. [CrossRef]

14. Kerrigan, J.F.; Parsons, A.; Tsang, C.; Simeone, K.; Coons, S.; Wu, J. Hypothalamic hamartoma: Neuropathology and epileptogenesis. Epilepsia 2017, 58 (Suppl. 2), 22-31. [CrossRef]

15. Parvizi, J.; Le, S.; Foster, B.L.; Bourgeois, B.; Riviello, J.J.; Prenger, E.; Saper, C.; Kerrigan, J.F. Gelastic epilepsy and hypothalamic hamartomas: Neuroanatomical analysis of brain lesions in 100 patients. Brain 2011, 134, 2960-2968. [CrossRef]

16. Ferrand-Sorbets, S.; Fohlen, M.; Delalande, O.; Zuber, K.; Bulteau, C.; Levy, M.; Chamard, P.; Taussig, D.; Dorison, N.; Bekaert, O.; et al. Seizure outcome and prognostic factors for surgical management of hypothalamic hamartomas in children. Seizure 2020, 75, 28-33. [CrossRef] [PubMed]

17. Corbet Burcher, G.; Liang, H.; Lancaster, R.; Cross, J.H.; Tisdall, M.; Varadkar, S.; Spoudeas, H.A.; Caredda, E.; Bennett, S.; Heyman, I. Neuropsychiatric profile of paediatric hypothalamic hamartoma: Systematic review and case series. Dev. Med. Child Neurol. 2019, 61, 1377-1385. [CrossRef] [PubMed]

18. Kim, J.H.; Yun, S.; Hwang, S.S.; Shim, J.O.; Chae, H.W.; Lee, Y.J.; Lee, J.H.; Kim, S.C.; Lim, D.; Yang, S.W.; et al. The 2017 Korean National Growth Charts for Children and Adolescents: Development, improvement, and prospects. Korean J. Pediatr. 2018, 61, 135-149. [CrossRef] 
19. Marshall, W.A.; Tanner, J.M. Variations in pattern of pubertal changes in girls. Arch. Dis. Child. 1969, 44, 291-303. [CrossRef]

20. Marshall, W.A.; Tanner, J.M. Variations in the pattern of pubertal changes in boys. Arch. Dis. Child. 1970, 45, 13-23. [CrossRef] [PubMed]

21. Greulich, W.W.; Pyle, S.I. Radiographic Atlas of Skeletal Development of the Hand and Wrist; Stanford University Press: Palo Alto, CA, USA, 1959.

22. Bayley, N.; Pinneau, S.R. Tables for predicting adult height from skeletal age. Revised for use with the greulich-pyle hand standards. J. Pediatr. 1952, 40, 423-441. [CrossRef]

23. Feuillan, P.P.; Jones, J.V.; Barnes, K.M.; Oerter-Klein, K.; Cutler, G.B., Jr. Boys with precocious puberty due to hypothalamic hamartoma: Reproductive axis after discontinuation of gonadotropin-releasing hormone analog therapy. J. Clin. Endocrinol. Metab. 2000, 85, 4036-4038. [CrossRef] [PubMed]

24. Jung, H.; Neumaier Probst, E.; Hauffa, B.P.; Partsch, C.J.; Dammann, O. Association of morphological characteristics with precocious puberty and/or gelastic seizures in hypothalamic hamartoma. J. Clin. Endocrinol. Metab. 2003, 88, 4590-4595. [CrossRef]

25. Li, C.D.; Luo, S.Q.; Tang, J.; Jia, G.; Ma, Z.Y.; Zhang, Y.Q. Classification of hypothalamic hamartoma and prognostic factors for surgical outcome. Acta Neurol. Scand. 2014, 130, 18-26. [CrossRef]

26. Debeneix, C.; Bourgeois, M.; Trivin, C.; Sainte-Rose, C.; Brauner, R. Hypothalamic hamartoma: Comparison of clinical presentation and magnetic resonance images. Horm. Res. 2001, 56, 12-18. [CrossRef]

27. Striano, S.; Meo, R.; Bilo, L.; Cirillo, S.; Nocerino, C.; Ruosi, P.; Striano, P.; Estraneo, A. Gelastic epilepsy: Symptomatic and cryptogenic cases. Epilepsia 1999, 40, 294-302. [CrossRef]

28. Valdueza, J.M.; Cristante, L.; Dammann, O.; Bentele, K.; Vortmeyer, A.; Saeger, W.; Padberg, B.; Freitag, J.; Herrmann, H.D. Hypothalamic hamartomas: With special reference to gelastic epilepsy and surgery. Neurosurgery 1994, 34, 949-958. [CrossRef]

29. Mittal, S.; Mittal, M.; Montes, J.L.; Farmer, J.P.; Andermann, F. Hypothalamic hamartomas. Part 2. Surgical considerations and outcome. Neurosurg. Focus 2013, 34, E7. [CrossRef]

30. Khawaja, A.M.; Pati, S.; Ng, Y.T. Management of epilepsy due to hypothalamic hamartomas. Pediatr. Neurol. 2017, 75, $29-42$. [CrossRef]

31. Arita, K.; Kurisu, K.; Kiura, Y.; Iida, K.; Otsubo, H. Hypothalamic hamartoma. Neurol. Med. Chir. 2005, 45, 221-231. [CrossRef]

32. Jung, H.; Parent, A.S.; Ojeda, S.R. Hypothalamic hamartoma: A paradigm/model for studying the onset of puberty. Endocr. Dev. 2005, 8, 81-93. [PubMed]

33. Chan, Y.M.; Fenoglio-Simeone, K.A.; Paraschos, S.; Muhammad, L.; Troester, M.M.; Ng, Y.T.; Johnsonbaugh, R.E.; Coons, S.W.; Prenger, E.C.; Kerrigan, J.F., Jr.; et al. Central precocious puberty due to hypothalamic hamartomas correlates with anatomic features but not with expression of gnrh, tgfalpha, or kiss1. Horm. Res. Paediatr. 2010, 73, 312-319. [CrossRef]

34. Feuillan, P.P.; Jones, J.V.; Barnes, K.; Oerter-Klein, K.; Cutler, G.B., Jr. Reproductive axis after discontinuation of gonadotropinreleasing hormone analog treatment of girls with precocious puberty: Long term follow-up comparing girls with hypothalamic hamartoma to those with idiopathic precocious puberty. J. Clin. Endocrinol. Metab. 1999, 84, 44-49. [CrossRef] [PubMed]

35. Ramos, C.O.; Latronico, A.C.; Cukier, P.; Macedo, D.B.; Bessa, D.S.; Cunha-Silva, M.; Arnhold, I.J.; Mendonca, B.B.; Brito, V.N. Long-term outcomes of patients with central precocious puberty due to hypothalamic hamartoma after gnrha treatment: Anthropometric, metabolic, and reproductive aspects. Neuroendocrinology 2018, 106, 203-210. [CrossRef] [PubMed] 